and shapes that side into the form and protection of a cell.

The chrysalis state is assumed in June, and lasts two weeks or more, and then again, after two years more or less of preparation, the butterfly is once more upon the wing - a stranded relic of the great Ice Age, like the alpine sandwort, Arenaria groenlandica, whose honeyed sweets it now robs.

\title{
VARIATION IN TRIDACTYLUS.
}

BY A. P. MORSE, WELleSley, MASS.

Tridactylus is a genus of small, fossorial crickets, allied in structure and habits to Gryllotalpa, the mole-cricket, and differing most noticeably from that genus, among several things, in being smaller in size and possessing remarkable saltatory powers.

Representatives of the genus occur over the greater part, at least, of the United States, and range in size from six to twelve millimeters in length when adult. They frequent the margins of streams and ponds, burrowing in the sandy loam of the banks and shores, and may be secured, when a station is discovered, by sweeping rapidly just above the ground with a net of cheesecloth or other close-meshed material. Owing to their alertness, activity, and leaping mode of progression close observations of their habits are exceedingly difficult to make out-of-doors and but little is known regarding them. Whether confinement would secure satisfactory results remains to be learned, but it is hoped that some one having an opportunity to do so will make the attempt and if possible discover the special func- tion of the remarkably modified anterior tibiae of the male in certain species and the significance of the variation noted below.

While collecting on Nantucket Island late in the afternoon of July 12, I900, I found a locality for Tridactylus on the shore of a small pond and captured several examples of both sexes. On the following day additional specimens were secured in the same place and about an adjoining pond. On my return home, examination after mounting disclosed an interesting state of affairs.

The 52 specimens taken on the two successive days in this one locality consist of one immature, 18 females, and 33 males. These exhibit no essential difference in color, size or markings leading one to infer the presence of two species, nor do the female examples differ in structural details. A close examination of the males, however, reveals a singular variation in the structure of the anterior tibiae. In about one third of the males the form is the same as that of the female (Fig. I), - more or less irregularly ovate in outline, terminating 
distally in four prominent, equidistant teeth, with the convex posterior face thickly set with hairs and a row of stouter hairs or spinules on the outer margin, the tarsus being inserted between the first and second teeth and lying on the anterior face. In three of the others, while the structure remains similar, the outline of the tibia has become subtriangular through the production of the inner side of the distal
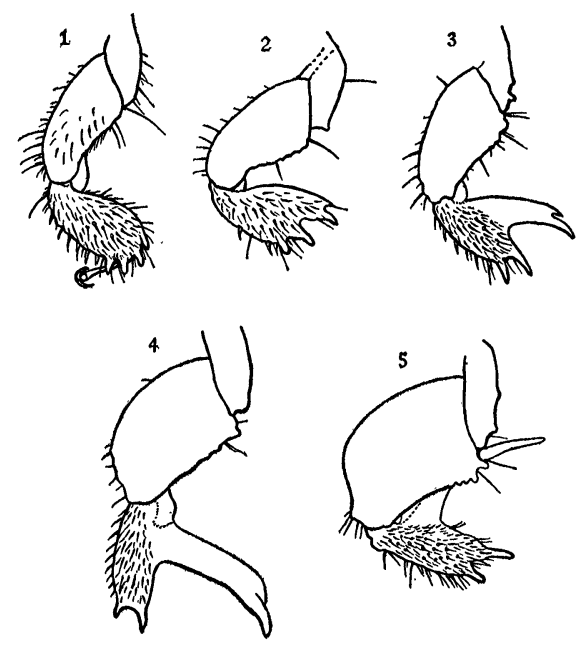

Tridactylus terminalis Scudd. Left anterior leg viewed from behınd. Fig. r. Female. Fig. 2. Male. Fig. 3. Male Fig. 4. Male. Fig. 5. Male; tibia closed upon the femur.

end (Fig. 2); in addition to this, there is a slight but distinct deepening of the fissure between the second and third teeth. This lengthening of what may be called the inner limb of the tibia and deepening of the emargination between the inner and outer limbs is exlibited by all the remaining specimens in progressive degree until we have a remarkably bifurcate organ (Figs. 4, 5) whose relation to the normal form would be made out with difficulty but for the series of connecting gradations.

In addition to this bifurcation and the elongation of the inner limb, the latter loses its hairy covering, the innermost tooth nearly disappears, the second is greatly prolonged into a backwardly directed claw-like organ, the third and fourth teeth (on the outer limb) become enlarged and produced, the angle between the two limbs becomes greater and greater, and the femur acquires tooth-like protuberances on its proximal, inner, ventral angle and becomes greatly enlarged (Figs. I-5). The gradation is so perfect (even in this relatively small series of examples) that it is impossible to draw any sharp line of demarcation between the specimens; sometimes, even, the right and left tibiae of the same insect are appreciably different in form. Of the 33 males, in ten the tibia is of normal ( $q$ ) form; in three others it is slightly but perceptibly modified, in one it is intermediate between Fig. I and Fig. 2, in two it is of the form of Fig. 2, in two intermediate between Fig. 2 and Fig. 3 , in four like Fig. 3 , in one midway between Fig. 3 and Fig. 4, in four but little less modified than in Fig. 4, and in six it has the form of Fig. 4 (open) and Fig. 5 (closed), the greatly elongated second tooth varying much in 
curvature (foreshortened in Fig. 4).

Each of the extremes of the series is thus represented by about one third of the specimens, and the intergrades by the remaining third, but these intergrades are so numerous and the gradation is so perfect that it is quite impossible to separate the specimens into two series. Nor is there reason on other grounds for so doing. The specimens evidently all belong to one species exhibiting a high degree of secondary sexual variation in the male, a variation whose function and value have yet to be determined, but the key to which may perhaps be secured by careful observation of the habits of the species.

This character-the form of the anterior tibiae of the male - has been used for many years in systematic treatises for distinguishing the species of this genus but it is now evident that its worth has been greatly over-rated and it must be regarded with suspicion and in some cases as worthless for that purpose. In certain forms, of which I have examined considerable series, this great variability apparently does not occur, the tibiae of the male and female being alike. The extremely bifurcate condition was recorded and figured by $\mathrm{Mr}$. Scudder in characterizing T. apicalis Say and T. terminalis Scudd. (Boston Journ. Nat. Hist., vii, p. 424,-1862). The form I have treated above is the latter of these-terminalis; and from material in Mr. Scudder's collection I am able to state that at least the normal ( $q$ ) form of tibia is found in males of apicalis also. Possibly terminalis may prove to be but a race of apicalis but until the genus is revised it is best to regard them as different, apicalis appearing slightly larger, paler in color, and usually having relatively longer wings. Both of these forms are widely spread over at least the eastern half of the United States, and are apparently not uncommon locally. It is hoped that anyone having an opportunity to do so will make observations on the habits of these interesting little crickets and attempt to discover the use of this peculiar modification of the tibiae and its value to the insect.

\section{PULVINARIA INNUMERABILIS RATHV.}

BY GEO. B. KING, LAWRENCE, MASS.

\section{Although Pulvinaria innumerabilis} Rathv. has been the subject of many published articles, together with illustrations of the species in its various stages of developments; it has become quite evident to the writer, that a more clear and comprehensive description should be given together with some descriptive notes of its variation and distribution; moreover it is hoped that the following 

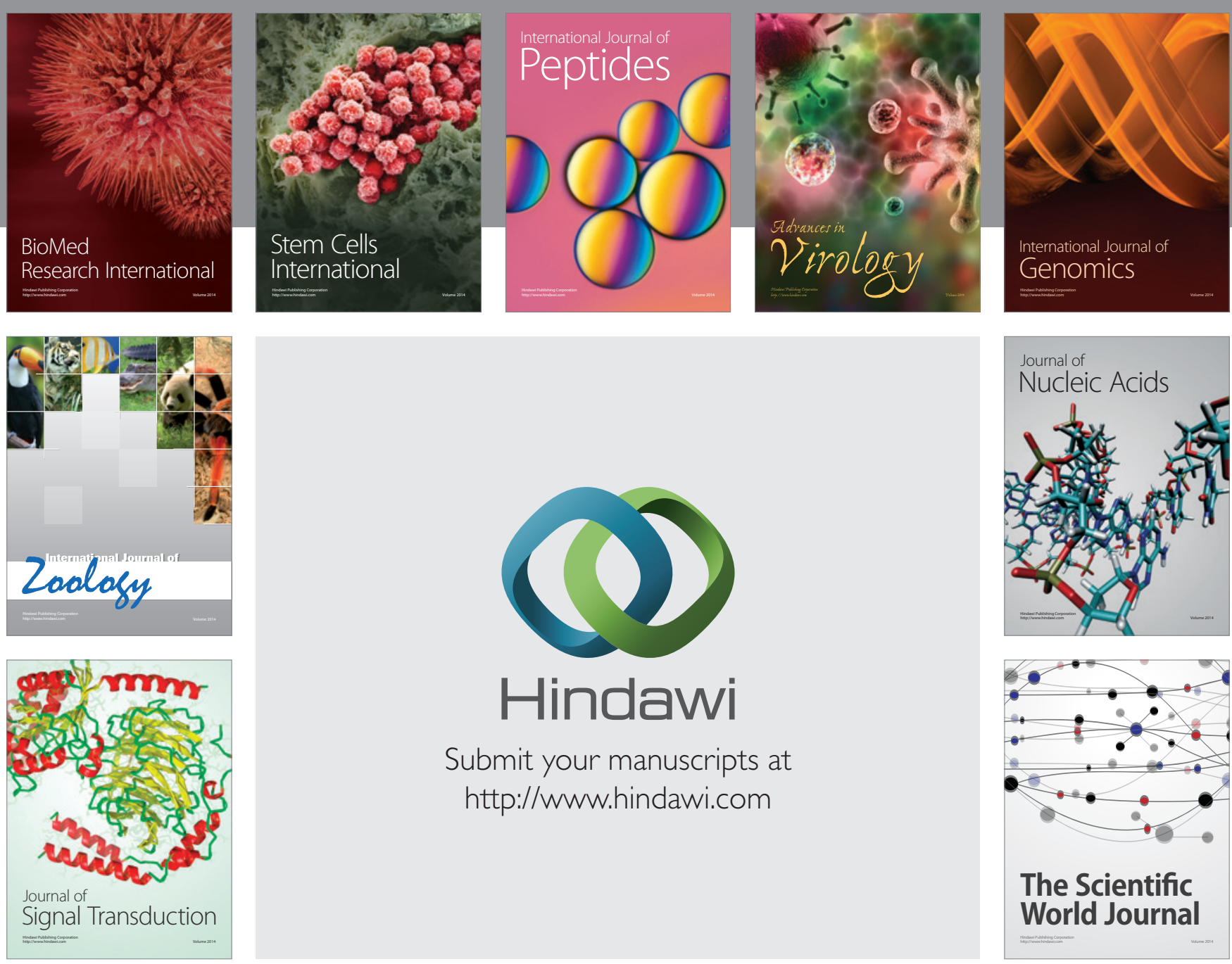

Submit your manuscripts at

http://www.hindawi.com
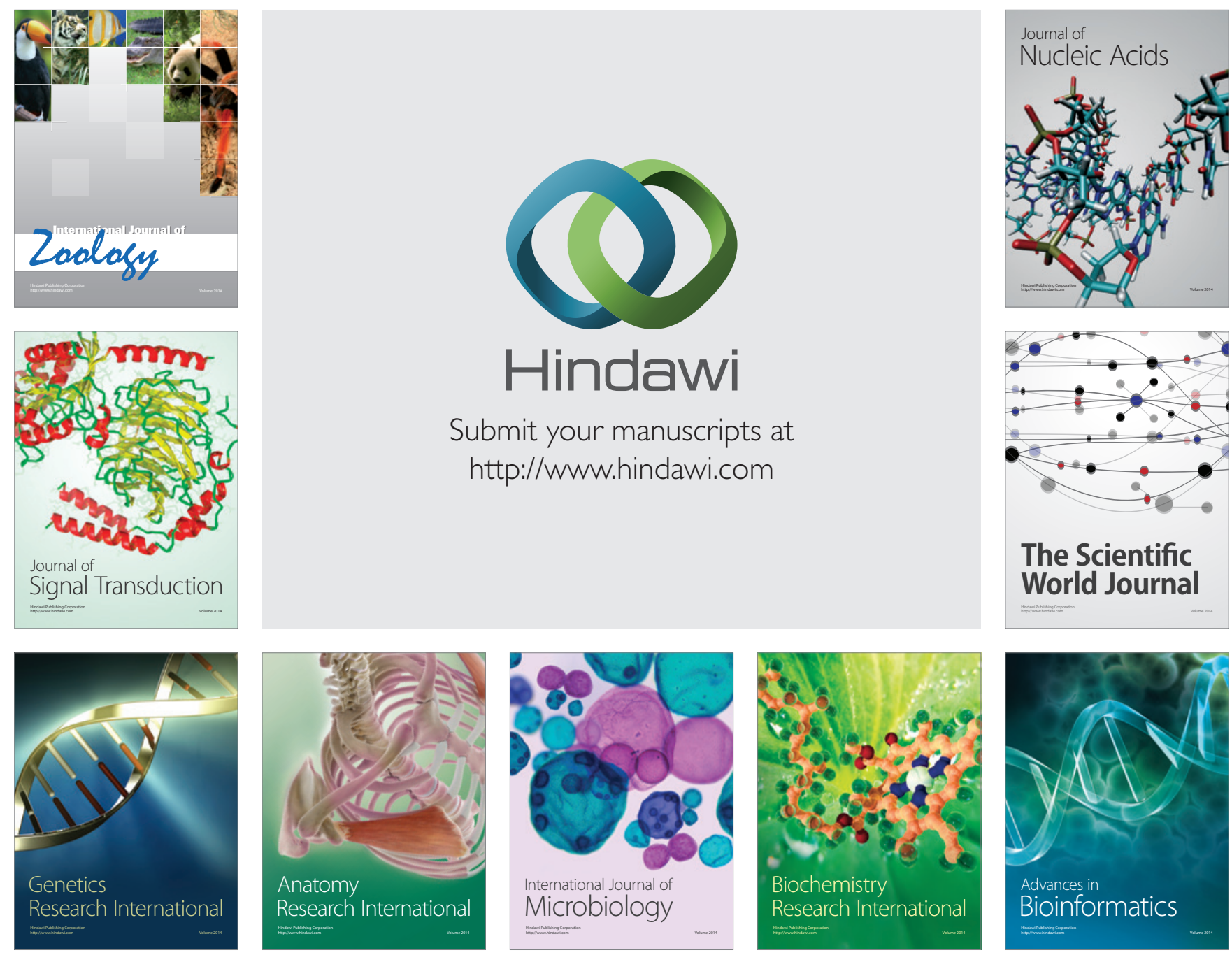

The Scientific World Journal
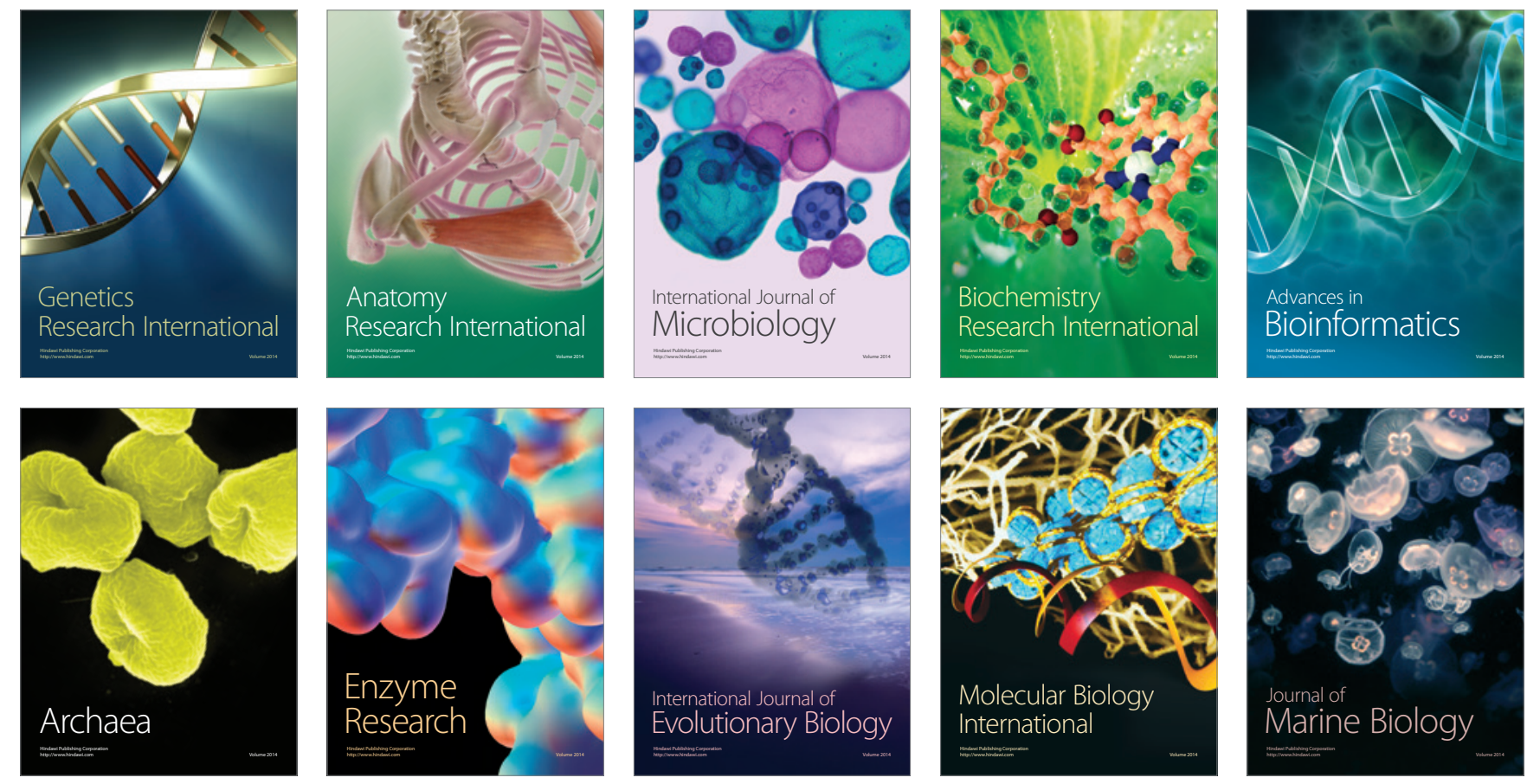